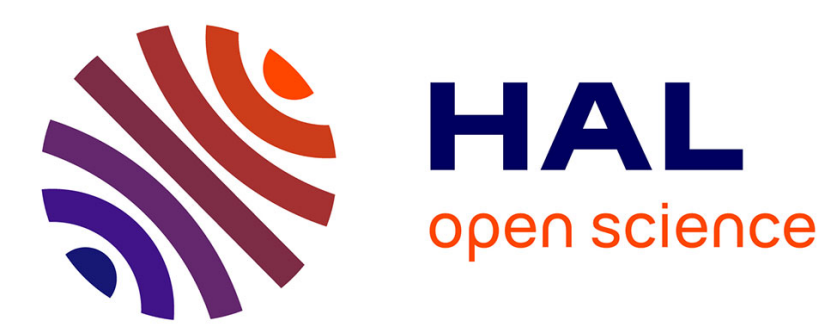

\title{
Classification and characterization of three phase voltage dips by space vector methodology
}

\author{
Vanya Ignatova, Pierre Granjon, Seddik Bacha, Frederic Dumas
}

\section{To cite this version:}

Vanya Ignatova, Pierre Granjon, Seddik Bacha, Frederic Dumas. Classification and characterization of three phase voltage dips by space vector methodology. IEEE International Conference on Future Power Systems 2005 (FPS 2005), 2005, Amsterdam, Netherlands. hal-00021536

\section{HAL Id: hal-00021536 https://hal.science/hal-00021536}

Submitted on 22 Mar 2006

HAL is a multi-disciplinary open access archive for the deposit and dissemination of scientific research documents, whether they are published or not. The documents may come from teaching and research institutions in France or abroad, or from public or private research centers.
L'archive ouverte pluridisciplinaire HAL, est destinée au dépôt et à la diffusion de documents scientifiques de niveau recherche, publiés ou non, émanant des établissements d'enseignement et de recherche français ou étrangers, des laboratoires publics ou privés. 


\title{
Classification and characterization of three phase voltage dips by space vector methodology
}

\author{
V. Ignatova, P. Granjon, S. Bacha and F. Dumas
}

\begin{abstract}
A new method is presented to identify and to characterize voltage dips measurements from power quality survey. This method is based on the space vector transformation, which describes the three power system voltages by one complex variable - the space vector. Its representation in the complex plane is used to classify voltage dips. Indeed, for a not disturbed system voltages, the space vector represents a circle in the complex plane with a radius equal to the nominal voltage. It follows the same shape for balanced dips, but with a smaller radius. For unbalanced dips, this shape becomes an ellipse with parameters depending on the phase(s) in drop, dip severity and phase angle shift. Further, space vector characteristics and zero sequence voltage are used for a more precise determination of the voltage dip type. The developed algorithm for voltage dips classification is validated by EMTP simulations and measurement data.
\end{abstract}

Index Terms-voltage dips (sags), characterization, classification, monitoring, power quality, power system, space vector.

\section{INTRODUCTION}

$\mathrm{V}$ OLTAGE dips are one of the most serious power quality problem and represent a major concern for the industry. They may cause interruption of industrial processes and may lead to economical losses and distorted quality products.

During the last years, equipments used in industrial plants have become more sensitive to voltage dips as a result of technology improvement and increased use of power electronics devices [1,2]. Thus, the automatic analysis classification and characterization of voltage dips have become an essential requirement for power quality monitoring. Three phase voltage dips are mainly characterized by their duration, magnitudes and phase angle jumps. The last two parameters determine the dip type (signature), which is relevant for the dip severity, as well as for the dip origin and location.

In order to determine the dip type, several methods are proposed in the literature. The most intuitive approach directly uses measured voltage waveforms for voltage dips

V. Ignatova is with the Laboratory of Electrical Engineering, Grenoble, France (e-mail: vanya.ignatova@leg.ensieg.inpg.fr).

P. Granjon is with the Laboratory of Images and Signals, Grenoble, France (e-mail: pierre.granjon@lis.inpg.fr).

$\mathrm{S}$. Bacha is with the Laboratory of Electrical Engineering, Grenoble, France (e-mail: seddik.bacha@leg.ensieg.inpg.fr).

F. Dumas is with Schneider Electric, Grenoble, France, (e-mail: frederic.dumas@schneider-electric.com) classification [3]. This method is easy to understand, but is not able to extract the characteristics of measured dips and consequently is not appropriate to automatic voltage dips analysis.

Another method [4] compares the six RMS values of phase and phase-to-phase voltages after removing the zero sequence component. The dip type is determined from the lowest magnitude voltage. This method does not give any phase information and can not provide a full dip characterization.

A recent method proposed in $[5,6]$ is based on the theory of symmetrical components. It quantifies three phase unbalanced voltage dips using one complex variable called characteristic voltage. However, for a complete and precise dip classification, additional characteristics are used, like zero sequence voltage and $\mathrm{PN}$ factor.

In this paper a new method for dip classification and characterization is developed. It is based on space vector transformation and leads to a more concise representation of voltage dips. The space vector methodology allows to extract characteristic features of the dip, to determine its type and evaluate its severity.

One of the main advantages of this method is the use of only the space vector and zero sequence voltage for voltage dips analysis. In addition, it offers an exhaustive classification and complete characterization of three phase voltage dips.

This paper is organized as follows: Section II describes the space vector transformation and its representation in the complex plane. Section III deals with voltage dips identification from space vector and zero sequence voltage. Finally, the complete method for voltage dips classification is described and illustrated with examples in section IV.

\section{SPACE VECTOR DEFINITION AND CHARACTERIZATION}

Space vector transformation can be directly derived from the Clarke transformation [7], defined as:

$$
\left(\begin{array}{l}
x_{\alpha}(t) \\
x_{\beta}(t) \\
x_{0}(t)
\end{array}\right)=\frac{2}{3}\left(\begin{array}{ccc}
1 & -\frac{1}{2} & -\frac{1}{2} \\
0 & \frac{\sqrt{3}}{2} & -\frac{\sqrt{3}}{2} \\
\frac{1}{2} & \frac{1}{2} & \frac{1}{2}
\end{array}\right)\left(\begin{array}{l}
v_{a}(t) \\
v_{b}(t) \\
v_{c}(t)
\end{array}\right)
$$

,where the coefficient $\frac{2}{3}$ is used to conserve magnitudes between the two coordinate systems.

The first two components of the Clarke transformation form 
the space vector (2) and the third one represents the zero sequence voltage (3)

$$
\begin{gathered}
\vec{x}(t)=x_{\alpha}(t)+j x_{\beta}(t)=\frac{2}{3}\left[\begin{array}{lll}
1 & e^{j \frac{2 \pi}{3}} & e^{j \frac{4 \pi}{3}}
\end{array}\right]\left[\begin{array}{l}
v_{a}(t) \\
v_{b}(t) \\
v_{c}(t)
\end{array}\right] \\
x_{0}(t)=\frac{1}{3}\left(v_{a}(t)+v_{b}(t)+v_{c}(t)\right)
\end{gathered}
$$

In terms of first harmonic, the three system voltages can be viewed as sinusoidal quantities before, during and after the fault. Under this assumption and using Euler's formula, they can be represented as the sum of two contra rotating vectors with angular frequency $\omega$. For example:

$$
v_{a}(t)=V \cos (\omega t+\varphi)=\frac{V}{2}\left(e^{j(\omega t+\varphi)}+e^{-j(\omega t+\varphi)}\right)
$$

The space vector is derived from the previous voltages and consequently, can be described as the sum of positive and negative angular frequency phasors:

$$
\vec{x}(t)=x_{p}(t) e^{j \omega t}+x_{n}(t) e^{-j \omega t}
$$

where $x_{p}$ and $x_{n}$ are complex numbers:

$$
x_{p}=\left|x_{p}\right| e^{j \varphi_{p}} \text { and } x_{n}=\left|x_{n}\right| e^{j \varphi_{n}}
$$

When magnitudes and initial phases of positive and negative angular frequency phasors are different, the space vector follows an ellipse shape in the complex plane (Fig. 1). Major axis $r_{m a j}$, minor axis $r_{\min }$ and inclination angle $\varphi_{i n c}$ of this ellipse depend on phasors magnitudes and phases [8]:

$$
r_{m a j}=\left|x_{p}\right|+\left|x_{n}\right| \quad r_{\min }=|| x_{p}|-| x_{n}|| \quad \varphi_{i n c}=\frac{1}{2}\left(\varphi_{p}+\varphi_{n}\right)
$$
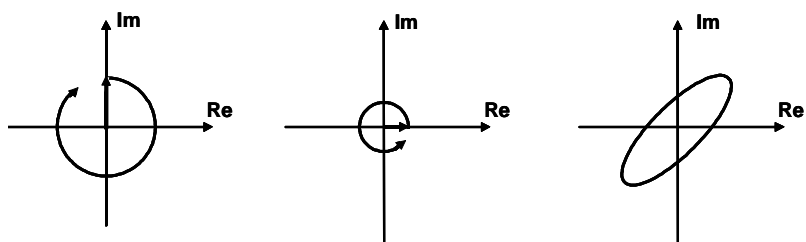

Fig.1 Representation of the space vector as the sum of two contra rotating vectors with positive and negative angular frequency, different magnitudes and initial phases

Note that if positive and negative angular frequency rotating phasors have the same magnitudes, $r_{\min }=0$ and the space vector is a straight line in the complex plane. Moreover, if the magnitude of one of these phasors is zero, $r_{\min }=r_{m a j}$ and the space vector becomes a circle.

In order to quantify the shape followed by the space vector in the complex plane, a shape index is introduced as follows:

$$
S I=\frac{r_{\min }}{r_{\text {maj }}}=\frac{|| x_{p}|-| x_{n} \mid}{\left|x_{p}\right|+\left|x_{n}\right|}
$$

Its value indicates the correlation coefficient of the space vector shape to a circle:

$$
\begin{array}{lll}
S I=1 & : & \text { circle } \\
0<S I<1 & : & \text { ellipse } \\
S I=0 & : & \text { straight line }
\end{array}
$$

\section{VOLTAGE DIPS IDENTIFICATION}

In a balanced sinusoidal three phase system, the three voltages have same magnitudes and their relative phase angle shift is $\frac{2 \pi}{3}$. As a result, the space vector is only composed of the positive angular frequency phasor, and represents a circle with radius equal to the nominal voltage in the complex plane. Voltage dips lead to changes in the space vector form. This paragraph demonstrates that for a balanced dip, the space vector follows a circle with a radius smaller than the nominal voltage. On the contrary, the space vector is composed of positive and negative angular frequency phasors for unbalanced dips, and then represents an ellipse in the complex plane. In order to distinguish different types of unbalanced voltage dips, the ellipse parameters and the zero sequence voltage are used.

\section{A. Unbalanced dips}

The following definitions are used: a dip with major voltage decrease in only one phase is called single phase dip; a dip with major drops on only two phases is denoted double phase dip.

\section{1) Single phase dips}

The voltage dips signature depends on several parameters: fault and measurement location, network and transformers grounding and type of measurements (phase to phase or phase to neutral). However, three types of single phase dips can be distinguished (Fig. 2). In the recent literature [9], they are denoted with letters B, D and F respectively.
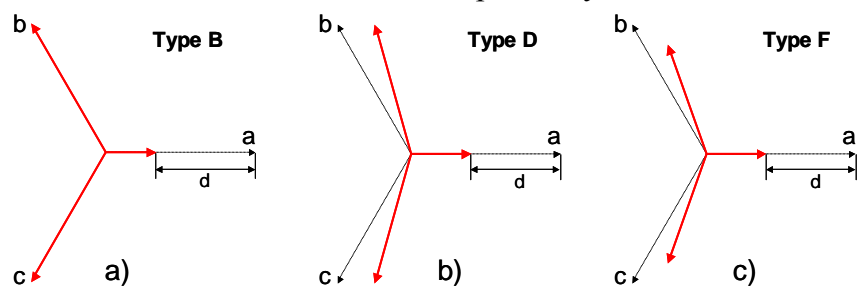

Fig. 2. Single phase dips between phase a and the neutral

The dip on Fig. 2a (type B) results from phase to neutral measurements at the fault location for grounded or low impedance grounded systems. For a major drop on phase a, this dip type is described by the following equations:

$$
\left\{\begin{array}{l}
v_{a}(t)=d V \cos (\omega t+\varphi) \\
v_{b}(t)=V \cos \left(\omega t+\varphi-\frac{2 \pi}{3}\right) \\
v_{c}(t)=V \cos \left(\omega t+\varphi-\frac{4 \pi}{3}\right)
\end{array}\right.
$$

, where $V$ is the nominal voltage and $d$ is a coefficient representing the dip depth $0 \leq d \leq 1$.

By applying Euler's formula on Eq. (8), the space vector and zero sequence voltage can be easily determined from (2) and (3) respectively: 


$$
\left\{\begin{array}{l}
\vec{x}(t)=\left(1-\frac{d}{3}\right) V e^{j(\omega t+\varphi)}+\frac{d}{3} V e^{j \pi} e^{-j(\omega t+\varphi)} \\
x_{0}(t)=-\frac{d}{3} V \cos (\omega t+\varphi)
\end{array}\right.
$$

In this case, the space vector is composed of positive and negative angular frequency phasors and describes an ellipse in the complex plane (Fig. 3a) with parameters obtained from (6). Its major axis is equal to the nominal voltage $r_{m a j}=V$ and its minor axis depends on the dip depth: $r_{\min }=\left(1-\frac{2}{3} d\right) V$. The inclination angle of this ellipse is $\varphi_{i n c}=\frac{\pi}{2}$.

For dips with major drops on phase $\mathrm{b}$ and $\mathrm{c}$ the space vector takes the same shape in the complex plane, but with different inclination angle: $\varphi_{i n c}=\frac{\pi}{6}$ for a drop on phase b (Fig. 3b) and $\varphi_{\text {inc }}=\frac{5 \pi}{6}$ for a drop on phase c (Fig. 3c).
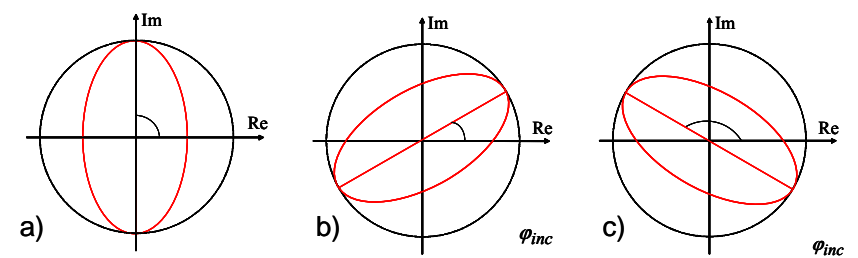

Fig. 3. Space vectors for a type B single phase dip on phase $a, b$ and $c$ respectively

The zero sequence voltage for this type of dips can not be neglected:

$$
x_{0}(t)=-\frac{d}{3} \cos \left(\omega t+\varphi-(n-1) \frac{2 \pi}{3}\right)
$$

, where $n=1,2,3$ for drops on phase a, b, c respectively. The dip type D shown on Fig. $2 b$ usually results from phase to phase measurements of two phase faults at the fault location, or well, from phase to neutral measurements of two phase faults not at the fault location. It is characterized by a major drop on one of the phases and small drops and phase angle shifts for the other two phases. In this case, the space vector is the sum of positive and negative angular frequency phasors, and represents an ellipse with axis:

$$
\left\{\begin{array}{l}
r_{\text {maj }}=V \\
r_{\min }=(1-d) V
\end{array}\right.
$$

The ellipse inclination angles are $\varphi_{\text {inc }}=\frac{\pi}{2}, \frac{\pi}{6}, \frac{5 \pi}{6}$ for a drop on phase $a, b$ and $c$ respectively. The zero sequence voltage is equal to zero.

The dip type F usually results from two phase-to-ground faults not measured at the fault location. The corresponding space vector follows an ellipse shape with parameters:

$$
\left\{\begin{array}{l}
r_{m a j}=\left(1-\frac{d}{3}\right) V \\
r_{\min }=(1-d) V
\end{array}\right.
$$

The possible ellipse inclinations are the same as for the two previous dip types and the zero sequence voltage is equal to zero.

The space vector characteristics and the zero sequence voltage value for the three previous single phase voltage dips are summarized in Table 1 . In these three cases, the space vector represents an ellipse $(S I<1)$ with inclination $\frac{5 \pi}{6}-n \frac{\pi}{3}$ ( $n=1,2,3$ corresponds to phase a, b, c respectively). The characteristics allowing the differentiation of the three types of single phase voltage dips are the zero sequence voltage and the ellipse major axis.

TABLE 1 SingLE PHASE VOLTAGE DIPS CHARACTERISTICS

\begin{tabular}{|c|c|c|c|c|c|}
\hline \multirow{2}{*}{ Type } & \multicolumn{4}{|c|}{ Space vector } & \multirow{2}{*}{$\begin{array}{c}\text { Zero sequence } \\
\text { voltage }\end{array}$} \\
\cline { 2 - 5 } & $S I$ & $\varphi$ inc & $r^{\text {min }}$ & ${ }^{r}$ maj & (1 \\
\hline B & $1-\frac{2}{3} d$ & $\frac{5 \pi}{6}-n \frac{\pi}{3}$ & $\left(1-\frac{2}{3} d\right) V$ & $V$ & $-\frac{d}{3} V \cos \left(\omega t+\varphi-(n-1) \frac{2 \pi}{3}\right)$ \\
\hline D & $1-d$ & $\frac{5 \pi}{6}-n \frac{\pi}{3}$ & $(1-d) V$ & $V$ & 0 \\
\hline F & $\frac{3(1-d)}{3-d}$ & $\frac{5 \pi}{6}-n \frac{\pi}{3}$ & $(1-d) V$ & $\left(1-\frac{d}{3}\right) V$ & 0 \\
\hline
\end{tabular}

2) Double phase dips

The three main double phase dips are presented in Fig. 4 and their corresponding space vector characteristics and zero sequence voltage are given in Table 2 . Note that for dip types $\mathrm{C}$ and $\mathrm{G}$, the variable $\mathrm{d}$ is a function of the phase angle shift and the drop of the phases in fault, and does not exactly represent the dip depth.

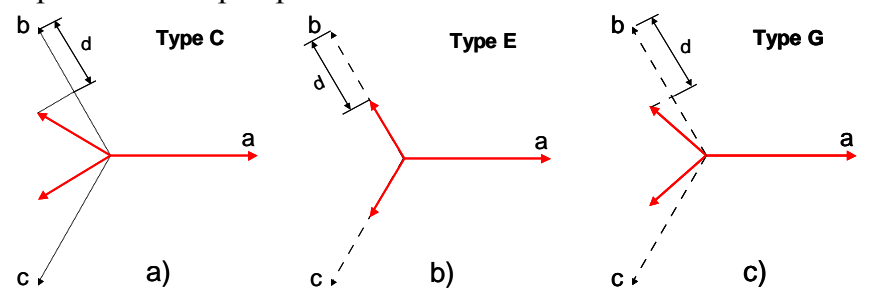

Fig. 4. Double phase dips on phases $b$ and $c$

TABLE 2 DOUBLE PHASE VOLTAGE DIPS CHARACTERISTICS

\begin{tabular}{|c|c|c|c|c|c|}
\hline \multirow{2}{*}{ Type } & \multicolumn{4}{|c|}{ Space vector } & Zero sequence voltage \\
\cline { 2 - 6 } & $S I$ & $\varphi_{i n c}$ & $r^{\text {min }}$ & ${ }^{m} a j$ & \\
\hline C & $1-d$ & $(1-n) \frac{\pi}{3}$ & $(1-d) V$ & $V$ & \\
\hline E & $\frac{3(1-d)}{3-d}$ & $(1-n) \frac{\pi}{3}$ & $(1-d) V$ & $\left(1-\frac{d}{3}\right) V$ & $\frac{d}{3} V \cos \left(\omega t+\varphi-(n-1) \frac{2 \pi}{3}\right)$ \\
\hline G & $\frac{3(1-d)}{3-d}$ & $(1-n) \frac{\pi}{3}$ & $(1-d) V$ & $\left(1-\frac{d}{3}\right) V$ & \\
\hline
\end{tabular}

In these three cases, the space vector is represented by a sum of two contra rotating phasors, and describes an ellipse in the complex plane with inclination angle: $\varphi_{\text {inc }}=0$ for voltage drops on phases $\mathrm{b}$ and $\mathrm{c}, \varphi_{\text {inc }}=\frac{\pi}{3}$ for drops on phases $\mathrm{a}$ and $\mathrm{b}$ and $\varphi_{i n c}=\frac{2 \pi}{3}$ for drops on phases a and c. Table 2 shows that the three types of double phase dips can be distinguished thanks to two parameters. The first one is the zero sequence 
voltage, which is equal to $x_{0}=\frac{d}{3} V \cos (\omega t+\varphi)$ for dip type $\mathrm{E}$ and $x_{0}=0$ for the other two dip types. The other parameter is the ellipse major axis, which is equal to the nominal voltage for the dip type $\mathrm{C}$ and inferior to the nominal voltage for the other two dip types.

\section{3) Unbalanced dips classification}

For unbalanced dips, the space vector represents an ellipse in the complex plane with parameters depending on the dip signature. The angle made by the major axis of the ellipse with respect to the real axis indicates the phase(s) with major drop as shown in Fig. 5. Single phase dips are denoted with S, double phase dips with $\mathrm{D}$, and phase(s) in drop are in lower case letters.

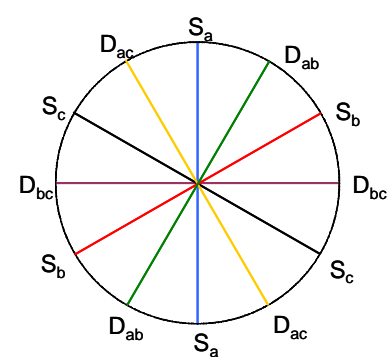

Fig. 5. Ellipse inclination angle for unbalanced dip

The zero sequence voltage and the ellipse major axis contribute to the dip classification, differentiating the dip types with the same ellipse inclination. The ellipse minor axis depends directly on the dip depth and can be used for detection of dip, and characterization of the dip severity.

Finally, it can be noted that the use of space vector for voltage dip analysis does not lead to a loss of information. Indeed, the voltage dip waveforms can be completely reproduced from the space vector and the zero sequence voltage.

\section{B. Balanced dips}

Balanced dip is a three phase dip without phase angle shifts (Fig. 6a). The corresponding space vector is only formed by one positive frequency phasor: $P(t)=(1-d) V e^{j(\omega t+\varphi)}$. It has a circle shape ( $S I=1)$, with radius depending on the dip severity $\left(r_{\min }=r_{m a j}=(1-d) V\right)$. The other dip characteristics are presented in Table 3 .
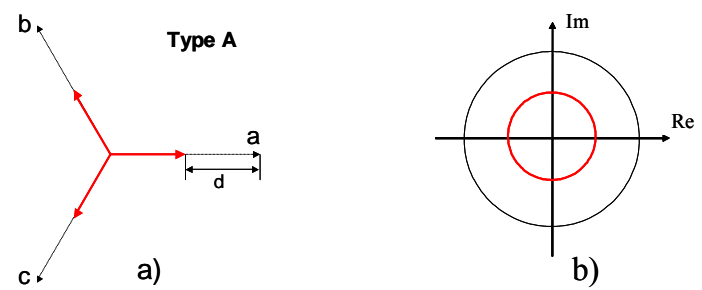

Fig. 6. Three phase balanced dip

TABLE 3 THREE PHASE VOLTAGE DIP CHARACTERISTICS

\begin{tabular}{|c|c|c|c|c|c|}
\hline \multirow[t]{2}{*}{ Type } & \multicolumn{4}{|c|}{ Space vector } & \multirow[t]{2}{*}{ Zero sequence voltage } \\
\hline & SI & $\varphi_{\text {inc }}$ & $r \min$ & $r_{m a j}$ & \\
\hline $\mathbf{A}$ & $V$ & - & $(1-d) V$ & $(1-d) V$ & 0 \\
\hline
\end{tabular}

\section{METHOD FOR VOLTAGE DIPS CLASSIFICATION}

In this section the algorithm for voltage dips classification is given in details and applied to measurement data obtained from the monitoring program of Schneider Electric. This program is implemented in a large number of customers sites in order to identify power system disturbances and propose solutions for power quality improvement.

\section{A. Algorithm}

The space vector method for voltage dips classification is presented in Fig. 7. It is assumed that the dip duration is over at least one cycle.

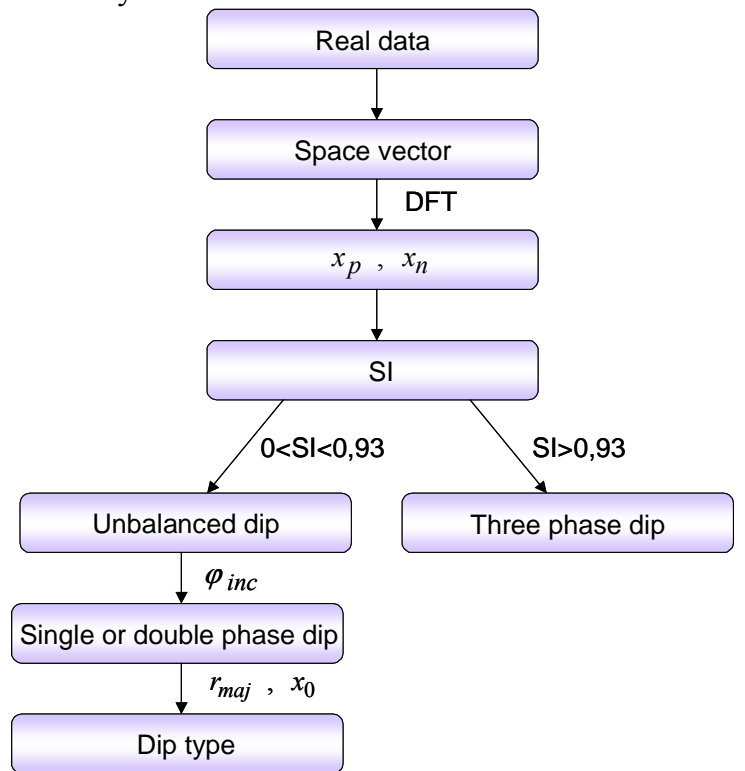

Fig. 7 Space vector method for voltage dips classification

The method is constituted by the following steps:

1) Estimate the space vector from real data by using expression (2).

2) Estimate positive and negative angular frequency phasors of the space vector for the fundamental frequency using complex-input discrete Fourier transform (DFT). The phasors are further used in order to obtain the space vector characteristics: ellipse axis and inclination (6), shape index (7).

Instead of using the DFT, space vector characteristics could be directly determined by using the space vector shape in the complex plane. Although this technique is more simple and requires less computational efforts, it may introduce important errors in dips classification. Indeed, measured voltages are often disturbed (noise, harmonics) and the space vector projection in the complex plane is not an ideal ellipse. A direct estimation of the space vector characteristics in this case leads to inaccuracy in the voltage dips classification and characterization.

This phenomenon can be illustrated with the example of the two-stage measured voltage dip presented in Fig. 8a. In both stages, dip voltages present a high harmonic distortion. The space vector shape and spectrum for the second stage dip are presented in Fig. $8 \mathrm{~b}$ and Fig. 8c respectively. Projected in the 
complex plane, the space vector represents a disturbed ellipse, and its spectrum confirms the presence of small harmonics and noise.
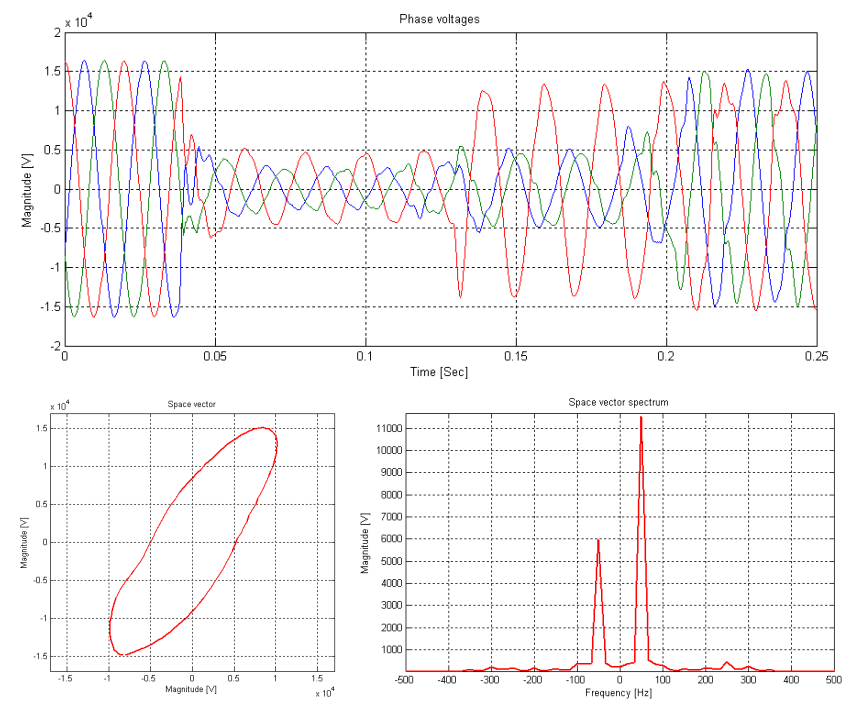

Fig. 8 A measured voltage dip (a), corresponding space vector projection in the complex plane (b) and space vector spectrum (c)

The negative impact of additive noise and harmonic distortion can be avoided by directly applying the DFT to the space vector. Indeed, the complex values given by the space vector spectrum at $\pm 50 \mathrm{~Hz}$ correspond to positive and negative fundamental angular frequency phasors $x_{p}$ and $x_{n}$ (see Eq. (5)). Their magnitudes are then used to calculate ellipse axis, and their phases determine ellipse inclination.

3) Determine if the dip is balanced or unbalanced by using the shape index $S I$.

Theoretically, the shape index is equal to 1 for three phase balanced dips and inferior to 1 for unbalanced dips. However, three phase measured dips usually present a shape index close, but inferior to these theoretical values due to the fact that phase voltage magnitudes often vary with respect to time. Therefore, a limit value of the shape index allowing the differentiation between unbalanced and balanced voltage dips should be estimated.

By definition, a voltage dip is a decrease to between 0.1 and 0.9 p.u. in rms voltage. Thus, the minimal dip depth is equal to $10 \%$ of the nominal voltage, which for unbalanced dips corresponds to a maximal shape index between 0.9 and 0.933 depending on the dip type (see Table 1 and 2 with $d=0.1$ ). Therefore, voltage dip with shape index superior to 0.933 can be considered as three phase balanced dip, and shape index inferior to 0.933 classify the dip as unbalanced.

4) For unbalanced dips, differentiate single and double phase dips and determine the phase(s) in drop by using the ellipse inclination angle as shown in Fig. 5.

As the ellipse inclination is not always exactly an integer multiple of $30^{\circ}$, a rounded index $k=$ round $\left(\frac{\varphi_{i n c}}{30^{\circ}}\right)$ is introduced in order to determine the dip type and facilitate the software implementation of the algorithm. Relations between the ellipse inclination, the index $k$ and the dip type are presented in Table 4.

TABLE 4 DIP TYPE ESTIMATION BY USING THE ELLIPSE INCLINATION

\begin{tabular}{|c|c|c|c|c|c|c|}
\hline$\varphi_{\text {inc }}$ & $0^{\circ} \pm 15^{\circ}$ & $30^{\circ} \pm 15^{\circ}$ & $60^{\circ} \pm 15^{\circ}$ & $90^{\circ} \pm 15^{\circ}$ & $120^{\circ} \pm 15^{\circ}$ & $150^{\circ} \pm 15^{\circ}$ \\
\hline$k$ & 0 & 1 & 2 & 3 & 4 & 5 \\
\hline Dip & $\mathrm{D}_{\mathrm{bc}}$ & $\mathrm{S}_{\mathrm{b}}$ & $\mathrm{D}_{\mathrm{ab}}$ & $\mathrm{S}_{\mathrm{a}}$ & $\mathrm{D}_{\mathrm{ac}}$ & $\mathrm{S}_{\mathrm{c}}$ \\
\hline
\end{tabular}

5) Determine the voltage dip type by using the zero sequence voltage and the major ellipse axis.

As in the case of the shape index, limit values for the ellipse major axis and the zero sequence voltage should be determined. These values can be fixed and estimated by an observation of the monitored network. Another possibility is to calculate them for every dip as a function of its depth $d$, which can be estimated by using $r_{\text {min }}$.

\section{B. Examples of algorithm applications}

The previous algorithm has been implemented in Matlab software and successfully applied to EMTP simulations in order to validate the proposed method.

This section presents different results obtained by this algorithm applied on measured voltage dips. Measurements were mostly performed at the medium voltage network, the sampling frequency was $1,6 \mathrm{kHz}$, and the three phases were acquired. Only dips with duration over one cycle are analyzed. Voltages during the fault are automatically isolated by a new space-vector-based segmentation algorithm, which will be detailed in a following paper. Zero sequence voltage and all space vector characteristics are given in p.u.

The developed algorithm is first applied to the voltage dip presented in Fig. 9.

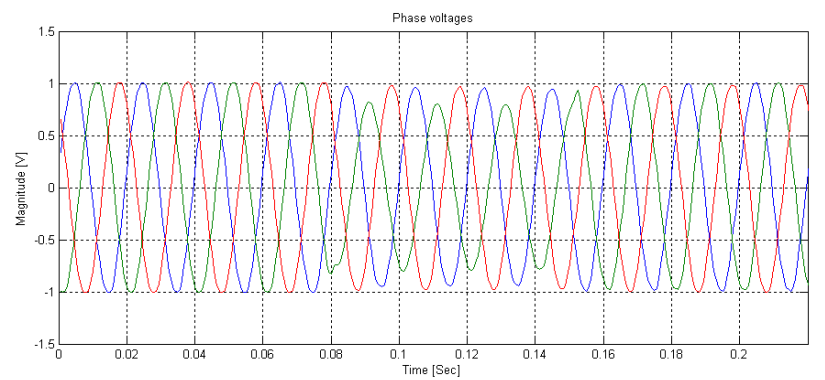

Fig. 9 Single phase measured voltage dip

The positive and negative fundamental frequency phasors are obtained from the DFT of the space vector: $x_{p}=0,91 e^{-j 70^{\circ}}$ and $x_{n}=0,09 e^{j 133^{\circ}}$. The shape index $S I=0,81$ indicates that the dip is unbalanced. The inclination angle $\varphi_{\text {inc }}=31,5^{\circ}$ corresponds to a single phase dip on phase $b$. The ellipse major axis $r_{\max }=1$ and the zero sequence voltage magnitude $x_{0}=0,02$ classify the dip as type $\mathrm{D}$. The ellipse minor axis is $r_{\min }=0,82$, therefore the dip depth can be estimated to $d=0,18 p u$.

The space vector for the voltage dip represented in Fig.10 is 
composed by a positive frequency phasor $x_{p}=0,78 e^{-j 158^{\circ}}$ and a negative frequency phasor $x_{n}=0,1 e^{j 38^{\circ}}$. The shape index $S I=0,76$ classifies the dip as unbalanced. The ellipse inclination $\varphi_{i n c}=120^{\circ}$ indicates that two phases are in drop: $a$ and $c$. The major ellipse axis $r_{\max }=0,88$ and the zero sequence voltage $x_{0}=0,05$ determine that the dip type is E. The minor ellipse axis $r_{\min }=0,67$ indicates that the dip depth is $d=0,33 p u$.

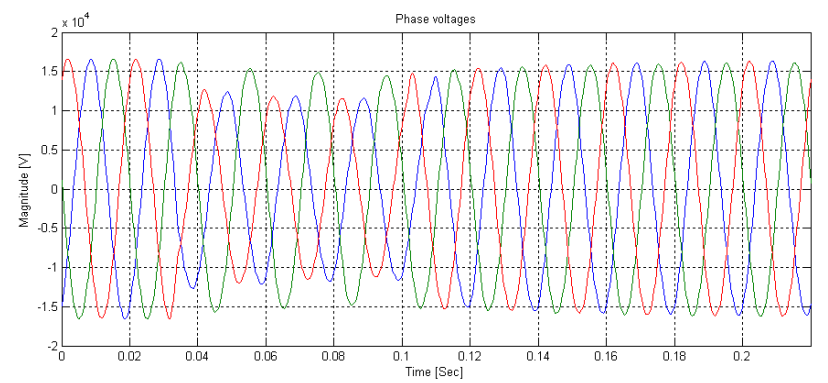

Fig. 10 Double phase measured voltage dip

The dip presented in Fig. 11 is characterized by a shape index $S I=0,94$ and is classified as a three phase balanced voltage dip since $S I>0.933$. Moreover, the dip depth is estimated to $d=0,5 \mathrm{pu}$.

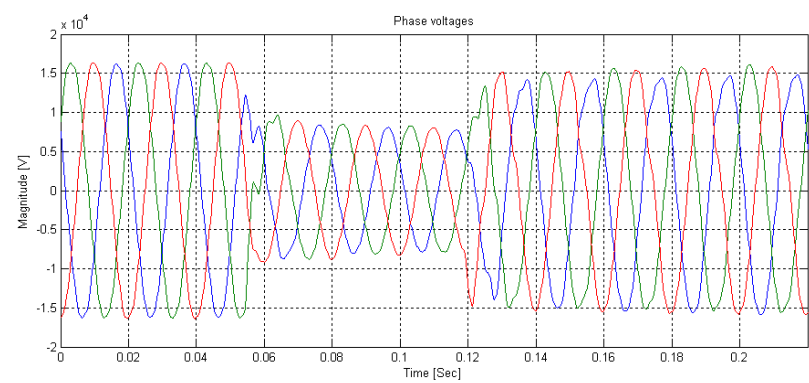

Fig. 11 Three phase measured voltage dip

\section{CONCLUSION}

A new method for voltage dips classification has been developed in this paper. It uses the space vector parameters and the zero sequence voltage in order to extract the characteristic features of the voltage dips and to determine their type. The space vector characteristics can also be applied to determine the dip severity (depth and phase angle shift).

The proposed method does not require many computational effort and is very appropriate for an automatic voltage dips analysis. The proposed algorithm was applied to EMTP simulation and measurements data and the obtained results has proved its accuracy.

\section{REFERENCES}

[1] M. McGranaghan; D. Mueller; M. Samotyj, Voltage sags in industrial systems, IEEE Transactions on industry applications, Vol. 29, No.2, pp. 397-403, March/April 1993

[2] T. Andersson, D.Nilsson, Test and evaluation of voltage dip immunity, STRI report, Sweden, 2002
[3] M.H.J. Bollen, L.D. Zhang, Different methods for classification of threephase unbalanced voltage dips due to faults, Electric Power Systems Research, Vol. 66, no.1 (July 2003), pp.59-69.

[4] Bollen, M. H. J. and Styvaktakis, S., "Characterization of Three-phase Unbalanced Sags, as easy as one, two, three", IEEE PES Summer Meeting 2000, Seattle, WA, USA, July 2000

[5] M. Bollen, L. Zhang, A method for characterization of three phase unbalanced dips from recorded voltage waveshapes, IEEE Telecommunication Energy Conference, INTELEC'99, June 1999, pp. 93

[6] L. Zhang, Three-phase unbalance of voltage dips, Licentiate thesis, Chalmers University of Technology, Dept Electric Power Engineering, Gothenburg, Sweden, November 1999.

[7] J. Aller, A. Bueno, T.Paga, Power system analysis using space vector transformation, IEEE Transactions on power systems, Vol. 17; No. 4, pp. 957-965, November 2002

[8] N. Bachschmid; P. Pennacchi; A. Vania, Diagnostic significance of orbit shape analysis and its application to improve machine fault detection, J. Braz. Soc. Mech. Sci. \& Eng. vol.26 no.2 Rio de Janeiro Apr./June 2004

[9] M. Bollen, Understanding Power Quality Problems : Voltage Sags and Interruptions, Wiley-IEEE Press, 1999

\section{BIOGRAPHIES}

Vanya Ignatova was born in Sofia, Bulgaria in 1979. She received her master degree in Electrical Engineering from the Technical University in Sofia in 2002. Currently, she is a Ph. D. student in the Laboratory of Electrical Engineering of Grenoble, France. Her main research interests include power quality, voltage sags and power system harmonics.

Pierre Granjon was born in France in 1971. He received the M.S. in electrical engineering from the University Center of Science and Technology, Clermont-Ferrand, France, in 1994 and the Ph.D. degree from the National Polytechnic Institute of Grenoble (INPG), France in 2000. He joined the Laboratory of Images and Signals (LIS) at INPG in 2001, where he holds a position as assistant professor. His general interests cover signal processing theory such as nonlinear signals and filters (higher order statistics, Volterra filters), non stationary signals and filters (cyclostationarity, LPTV filters) and active control. His current research is mainly focused on signal processing applications in electrical engineering such as fault diagnosis in electrical machines and power networks.

Seddik Bacha received his Engineer and Master from National Polytechnic Institute of Algiers respectively in 1982 and 1990. He joined the Laboratory of Electrical Engineering of Grenoble (LEG) and received his PhD and HDR respectively in 1993 and 1998. He is presently manager of Power System Group of LEG and Professor at the University Joseph Fourier of Grenoble. His main fields of interest are power electronics systems, modeling and control, power quality, renewable energy integration.

\section{Frederic Dumas}

